\title{
A decade of RAD51C/D: Germline pathogenic variants and their phenotypic landscape
}

\author{
Jacopo Boni ${ }^{1}$, Aida Idani ${ }^{1}$, Carla Roca ${ }^{1}$, Lídia Feliubadaló ${ }^{2}$, Eva Tomiak ${ }^{3}$, Evan Weber $^{4}$, \\ William Foulkes ${ }^{4}$, Alex Orthwein ${ }^{5}$, Zaki el Haffaf ${ }^{6}$, Conxi Lazaro ${ }^{1}$, and Barbara Rivera ${ }^{1}$ \\ ${ }^{1}$ IDIBELL \\ ${ }^{2}$ Catalan Institute of Oncology \\ ${ }^{3}$ Children's Hospital of Eastern Ontario \\ ${ }^{4}$ McGill University Health Centre \\ ${ }^{5}$ McGill University \\ ${ }^{6}$ Centre Hospitalier de l'Universite de Montreal
}

September 25, 2021

\begin{abstract}
Defects in DNA repair genes have been extensively associated to cancer susceptibility. Germline pathogenic variants (GPV) in genes involved in homologous recombination repair pathway predispose to cancers arising mainly in breast and ovary, but also other tissues. The RAD51 paralogs RAD51C and RAD51D were included in this group 10 years ago, when germline variants were associated to non-BRCA1/2 familial ovarian cancer. However, whether GPVs in these genes are associated with other cancers remains unknown. Here, we have reviewed the landscape of RAD51C and RAD51D germline variants in cancer reported in the literature during the last decade, curating a total of 341 variants and the phenotypes found in families with RAD51C/D variant carriers. A comprehensive catalogue has been generated pinpointing to the existence of recurrent variants in both genes. Investigation of pedigrees found fourteen other cancer types reported more than five times in families with carriers of RAD51C/D pathogenic variants. Among those, colorectal (3.72\% and 4.43\%) (RAD51C/D respectively), pancreatic $(1.19 \%$ and $0.86 \%)$, lung $(1.27 \%$ and $2.58 \%)$, prostate $(1.56 \%$ and $1.48 \%)$, and leukemia $(1.56 \%$ and $1.11 \%)$ cancer were the most prevalent types. This work highlights how both genes might confer susceptibility to a broader spectrum of cancer types than ovary and breast.
\end{abstract}

\section{Hosted file}

RAD51C-D_MutationUpdate(2).pdf available at https://authorea.com/users/436421/articles/ 538745-a-decade-of-rad51c-d-germline-pathogenic-variants-and-their-phenotypic-landscape

\section{Hosted file}

RAD51C-D_MutationUpdate(2).docx available at https://authorea.com/users/436421/articles/ 538745-a-decade-of-rad51c-d-germline-pathogenic-variants-and-their-phenotypic-landscape 

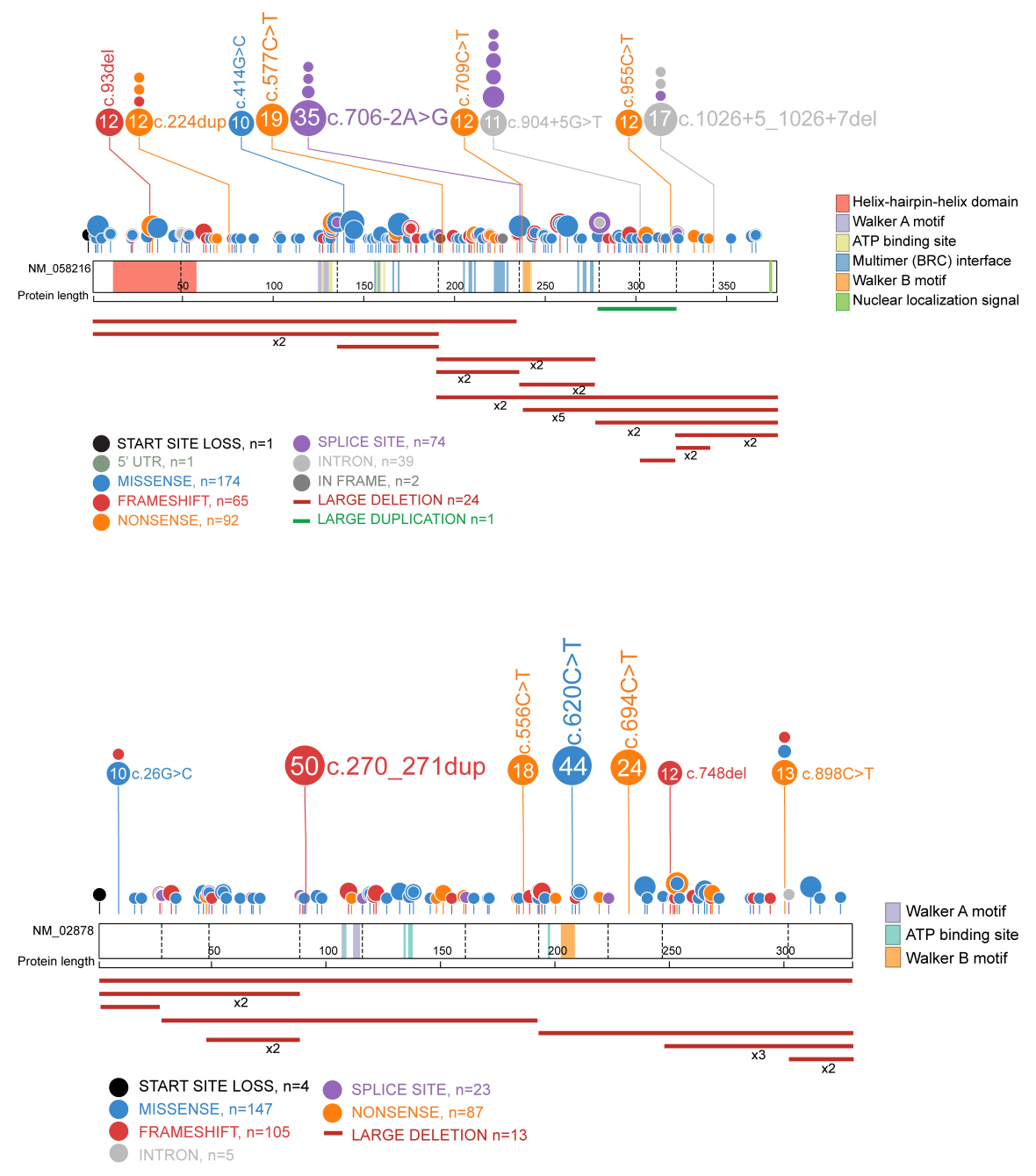

A
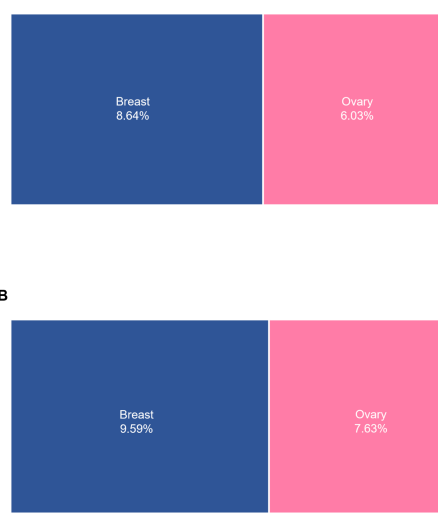

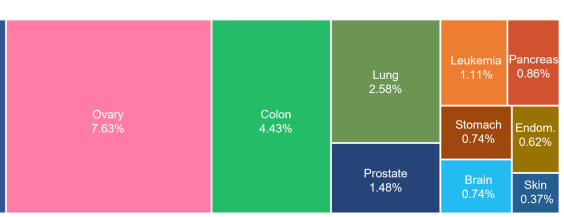

c
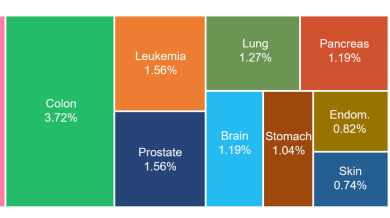

c $3^{3^{9^{10}}}$

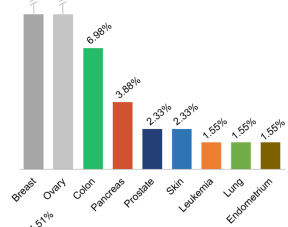

。

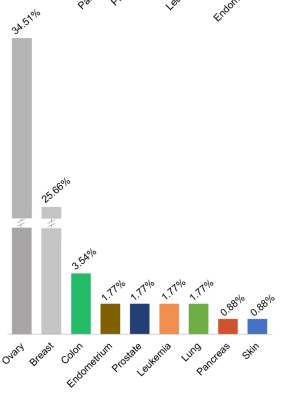

